I bave known ulceration to occur in this morbid structure, when a deep and foul sore, excessively sensitive, is formed. It may be healed by rest, but it recurs when the patient resumes the usual habits.

Now the cause of these corns will generally be found to proceed from a tense condition of some of the important tendons, that most frequently affected being the tendo-Achillis. When it is so contracted, the foot cannot be raised beyond a right angle; and it follows that the weight of the body is unduly thrown on the fore part of the sole of the foot, where the corn speedily forms. The contraction of the tendon may be so slight as to need careful examination for its detection; but so long as it exists the cause of the corn remains, and it will be found that any other measure less than the division of the tendon will be only palliative. The subcutaneous division of the tendon, its elongation, and the restoration of the foot to its normal bearings must be conducted on the usual principles of orthopæric surgery. The vractice has been adopted many years at the Orthopædic Fospital; but it is not so generally known as, in $\mathrm{my}^{\circ}$ opinion, is desirable.

New Bridgcsstreet, Dec. 1859.

ON A

\section{CASE OF PURPURA, READILY YIELDING TO GALLIC ACID AND MERCURY.}

By W. WHALleY, Esq, M.R.C.S., Yorkshire.

ON the 4 th of May, 1859, I was hastily summoned to attend a patient suffering from purpura. The following is a correct report of the case :-

Elizabeth $\mathrm{W} \longrightarrow$, aged twenty-four years; single. She is rather tall, and of sanguine temperament. Has worked at a factory as a weaver for eleven years, and has enjoyed robust health the whole of that time. She cannot recollect ever having suffered from any disease, except on one occasion from tic. She has always had good and sufficient food, and rarely passed a day without eating vegetables at dinner. She states that nearly the whole of the blood-spots came out on the night of the 30 th of April, 1559.

Present state (May 4th.) - The conjunctiva of the right eye appears like a bright-red, membranous-looking bag, from the presence of extravasated blood, similar morbid changes having occurred at the inner part of the left eye; they combine in im. parting to the countenance an expression of anxiety, some. what hideous to look upon. Round livid and purple spots are seen on the trunk, thighs, legs, and back of the hands, but more particularly on the breast and arms, which are thickly studded with irregular blotches of ecchymoses, of various sizes, On looking into the mouth, blood is seen oozing from numerous livid spots on the mucous membrane lining the interior of that eavity and the fauces; it has continued to ooze from the mouth without intermission since the 1st of Niay. The patient states that nearly a cupful of blood has drained from her mouth during the past night. Tongue coated and moist; breath fotid; skin hot and perspiring; the functions of the respiratory organs healthy; pulse frequent and compressible; bowels costive; urine loaded with blood; catamenia have appeared regularly; has no pain, but complains of languor and depression of spirits. Ordered, a cathartic mixture, chiefly consisting of a solution of sulphate of magnesia, to be given in ounce doses every two hours until the bowels are freely acted upon.

5th.-Morning: The bowels have been moved several times during the night; the tongue somewhat cleaner; skin feels more natural; the hæmorrhage from the mouth unabated; urine still loaded with blood; the extravasation has made considerable encroachment on the left eye during the past night. Prescribed a powder, consisting of the chloride of mercury and gallic acid, of each three grains every four hours; also one grain of the sulphate of quinine in solution every four hours; diet to consist of beef-tea, light broth, and farinaceous food.

6th.-Evening: Hæmorrhage from the mouth considerably diminished and very pale; urine almost colourless, and contains but very slight traces of hæmorrhage; extravasation into the left eye has ceased; no more spots have appeared since last night; tongue continues furred and moist; breath still feetid bowels costive; skin hot; pulse frequent, but feeble. Ordered, the cathartic mixture as before, after which a powder, consisting of the chloride of mercury and gallic acid, of each two grains, to be taken every four hours; diet as before. 7th. - The hæmorrhage has entirely ceased. Symptoms of incipient ptyalism are apparent. The powders to be discontinued; the quinine and diet to be continned as before.

9th. -No hæmorrhage since last visit, with the exception of a small amount which was observed in one of the motions yesterday morning; uriné quite natural; bowels costive; skin hot; tongue coated. Cathartic mixture to be repeated, after which the quinine as before.

1Ith. - No hæmorrhage; feels stronger; appetite improved; could eat more if the tongue and gums were not sore. Prescribed ten drops of the tincture of the sesquichloride of iron in water every four hours.

13th.-General health much improved; tongue and gums much better, but complains of slight difficulty of deglutition. Ordered, a gargle, consisting of a solution of alum and borax, to be used frequently.

17th. - The general health has continued to improve since last visit, but the frequent administration of purgatives has been requisite to obviate costiveness; throat and mouth almost well. Tonic mixture to be continued.

23rd.- Health decidedly improved; assists in household work; the spots have diminished in number; others are rapidly disappearing, and present a variety of shades of colour; the conjunctive have undergone but little, if any, change in colour. Ordered to take a mixture, consisting of the infusion of quassia and the tincture of the sesquichloride of iron, three times a day.

After this visit I did not again see the patient until the 3rd of September, when she called at my house, and informed me that after spending a few weeks with her friends, she resumed her work, and that at present her health is as good as it was before the attack of purpura; the right eye is scarcely restored to its original condition, being traversed by numerous lines of a pale-yellow hue.

In calling the attention of my professional brethren to this case, I more especially wish them to mark the happy results that supervened upon the exbibition of gallic acid-a remedy which, so far as I have been able to ascertain, has not before been administered under similar circumstances. The therapentical effects of gallic acid, as a powerful astringent, and a remedy of great value in passive hremorrhages from mucous surfaces, and especially from the urinary organs, are too well known to require comment" in this place. In the above case it will be seen that the powders containing gallic acid and calomel were commenced on the morning of the 5th of May. On visiting the patient in the afternoon of the 6 th of May she informed me that in a few hours after she had commenced taking the powders, the bleeding from her mouth and kidneys began to diminish, and was much paler in colour; and it is from this time she dates her amendment.

Oxenhope, near Keighley, Nor. 1859.

\section{a allitror}

OF THE PRACTICE OF

\section{MEDICINE AND SURGERY IN THE}

\section{HOSPITALS OF LONDON.}

Nulla est alia pro certo noscendi via, nisi quam plurimas et morborum et dissectionum historias, tam aliorum proprias, collectas habere et inter se comparare. -Mongagri, De Sed. et Caus. Morb., lib. 14. Proœmium.

\section{KING'S COLLEGE HOSPITAL.}

MEDULLARY TUMOUR SPRINGING FROM THE FIBULA; AMPUTATION AT THE KNEE-JOINT; FATAL RESULT.

(Under the care of Mr. Fengusson.)

WhILST some attention has of late years been paid to the subject of excision of diseased knee-joints, as a more favourable proceeding than amputation of the limb higher up, another suitable operation in which this important articulation is to be considered has been somewhat overlooked, although it has been noticed by a few of our metropolitan surgeons: we allude to amputation of the leg at or through the knee, in place of removal above the joint. In the introduction of any new 